\title{
Infância e conhecimento: princípios e bases à luz da teoria histórico-cultural
}

\author{
Aretha Amorim Bellini* \\ Elaine Sampaio Araújo**
}

\begin{abstract}
RESUMO: Este estudo visa contribuir com a discussão acerca dos princípios e bases para uma pedagogia humana a partir da teoria histórico-cultural. Para tanto, lançamos luzes sobre os conceitos de infância e conhecimento para compreender a atividade de estudo da criança, defendida por Leontiev e Vigotski. Tais reflexões têm como pressuposto a criança como um sujeito concreto e histórico, ou seja, assume-se que o seu desenvolvimento é baseado nas contradições das determinações sociais que se materializam na sociedade atual, que passam também pelo conhecimento historicamente produzido e apropriado no cenário escolar.
\end{abstract}

PALAVRAS-CHAVE: Conhecimento. Infância. Teoria histórico-cultural. Pedagogia humana.

\section{Childhood and knowledge: principles and bases in the light of historical-cultural theory}

\begin{abstract}
This study aims to contribute to the discussion on the principles and bases for a human pedagogy based on historical-cultural theory. To this end, we shed light on the concepts of childhood and knowledge to understand the child's study activity, advocated by Leontiev and Vigotski. These reflections are based on the assumption that the child is a concrete and historical subject. In other words, they assume that her development is based on the contradictions of the social determinations that take place in the current society, which also pass through the knowledge that has been historically produced and appropriated in the school scenario.
\end{abstract}

KEYWORDS: Knowledge. Childhood. Historical-Cultural Theory. Human Pedagogy.

\footnotetext{
* Mestra em Educação pela Universidade de São Paulo (USP), pedagoga na Prefeitura Municipal de Franca. Endereço eletrônico: arethabellini@gmail.com.

${ }^{* *}$ Livre-docente pela Faculdade de Filosofia, Ciências e Letras de Ribeirão Preto (USP), docente da USP. Endereço eletrônico: esaraujo@usp.br.
} 
Infância na perspectiva da teoria histórico-cultural: reflexões sobre o ser criança no mundo do capital

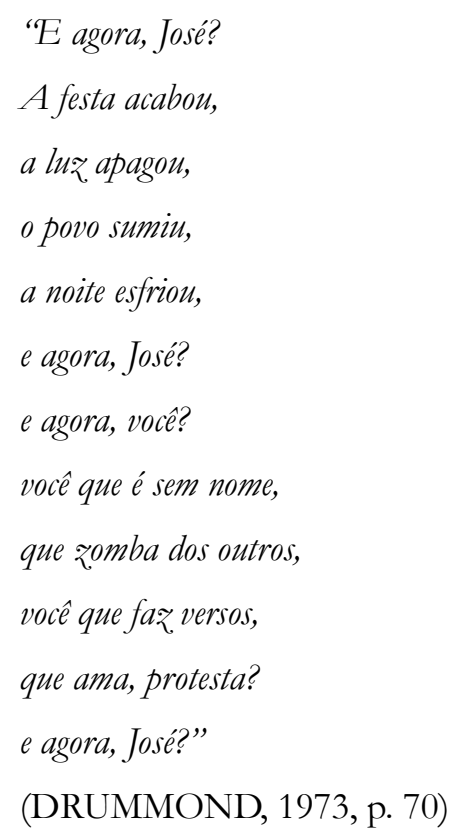

Com base na compreensão das teses da teoria histórico-cultural, o homem é um ser social e biológico, assim, também a criança é, por sua vez, s é social e biologicamente constituída. A teoria histórico-cultural distancia-se de concepções que defendem que a criança possui um estado "natural" referente ao seu desenvolvimento, com suas habilidades e capacidades humanas organizadas a partir de fases predeterminadas.

De acordo com Charlot (1983), concepções maturacionistas e ambientalistas defendem a criança em seu estado puro, sendo o desenvolvimento infantil uma expressão da natureza, como em Emílio, de Rousseau (1995), que representa um sujeito sem relação com a realidade social, ou seja, um ser predominantemente da natureza, com suas transformações vinculadas a ela. Defender condutas naturais no desenvolvimento infantil implica adotar uma concepção simplificada e naturalizada, que se afasta do ser criança na sua forma real e concreta.

Compreender a infância desvinculada do contexto social significa valer-se de uma concepção de criança presente na Idade Média, período em que ela participava do mundo dos adultos, com as mesmas roupas, comportamentos e costumes destes. Ou seja, as crianças vivenciavam os mesmos interesses e gostos e não possuíam particularidades em seu desenvolvimento. $\mathrm{Na}$ “idade que planta os dentes" (ARIÈS, 1978, p. 6), a criança era tida como frágil e desvalorizada, uma vez que não possuía o amadurecimento de um adulto e tampouco era reconhecida como um ser em pleno desenvolvimento.

Vygotsky (1988) ressalta que a criança não deve ser compreendida como um adulto em miniatura. Há diversos fatores psíquicos, sociais e físicos que diferenciam uma criança de um adulto, de maneira qualitativa e quantitativa. As transformações que acontecem no desenvolvimento infantil são constantes 
e não lineares e ocorrem em função das relações que a criança estabelece com o seu campo social:

[...] o desenvolvimento infantil não é linear, causado por acumulações sucessivas. Há metamorfoses, revoluções radicais no processo de desenvolvimento pelas quais passa a criança, que irão garantir sua passagem de ser biológico para ser cultural. Essas metamorfoses não são produzidas biologicamente pelo curso natural do desenvolvimento, mas sim pela inserção da criança no mundo histórico-cultural (ASBAHR, 2011, p. 40).

Cada criança está inserida em um contexto histórico-cultural diferente, criando um diálogo entre suas vivências e uma realidade histórica e cultural particular. Os sentidos pessoais que cada sujeito elabora perpassam as experiências realizadas no social. As condições concretas para que ocorra o desenvolvimento humano não são as mesmas para todos os sujeitos. Isso resulta que também as mudanças psicológicas da personalidade da criança relacionam-se com as mediações culturais possibilitadas a essas crianças._(LEONTIEV, 2004).

As vivências presentes na infância desencadeiam diversas aprendizagens. Por meio delas, a criança, em diferentes contextos, seja familiar ou escolar, apropria-se das experiências sociais da humanidade, na brincadeira, no estudo, tomando para si os conhecimentos construídos socialmente. A criança, pelas suas experiências, apropria-se da cultura da humanidade. Como cultura da humanidade se reconhece os conjuntos de costumes e de objetos criados ao longo da história da humanidade. Conforme ilustra Mello (2015, p. 5),

A esse conjunto de coisas criadas ao longo da história pelos homens e mulheres que viveram antes de nós e que continuam a ser criadas pelos que vivem hoje - das necessidades mais essenciais às mais superficiais - chamamos cultura. Esta é composta pelos hábitos e costumes, pela ciência e pelas técnicas, pelas diferentes formas de expressão, pelos objetos materiais e não materiais, pelos instrumentos - entendidos como objetos especiais que ampliam as possibilidades do corpo humano e a atividade humana, como o lápis e a tesoura e os próprios instrumentos musicais.

Diante dessa cultura da humanidade, a criança é constituída, formando um repertório de vida por meio de suas vivências sociais, tendo no outro sua referência de humano.

A ideia de impotência fisiológica da criança é uma ideia abstrata, como já vimos quando tratamos da significação ideológica da ideia de infância. Certamente, se a criança se encontrasse só num mundo natural, seria incapaz de sobreviver; ainda é preciso matizar essa afirmação, como o demonstra o exemplo das crianças selvagens. Mas, precisamente, a criança não está só e não vive num meio natural, mas num meio social. Cometemos um erro quando imaginamos condições de vida "naturais" da criança para transpô-las em seguida para a ordem social. Num meio de vida não-humano uma criança abandonada a seus próprios meios teria poucas possibilidades de sobreviver (CHARLOT, 1983, p. 248).

As relações sociais são forças motivadoras, "força motriz", para o desenvolvimento humano. Diante disso, o lugar social que a criança ocupa é de fundamental importância para o seu desenvolvimento. A ausência da ordem social, do contato humano, configura um contexto afastado das relações humanas, fato que não possibilita condições para formar um sujeito social, organicamente vivo, 
o qual reconhece sentidos em suas vivências e experiências na coletividade. É imprescindível o contato com o outro para que ocorra o compartilhamento de saberes e sentimentos.

As concepções sobre a infância orientam as práticas educacionais nas escolas e em quaisquer contextos sociais e podem ser promotoras ou entraves para o desenvolvimento das capacidades e habilidades humanas nas crianças. Para que as crianças estabeleçam significados e sentidos nos objetos presentes em sua cultura, elas próprias necessitam vivenciar e experimentar ações, relacionando-se com os objetos culturais. Só assim conseguirão se apropriar dos significados atribuídos aos objetos e desenvolver suas capacidades a partir de tais vivências e experimentações (VIGOSTKI, 2002).

As condições concretas exercem influência tanto sobre o conteúdo de um estágio individual do desenvolvimento como sobre o curso total do processo de desenvolvimento psíquico como um todo. Exemplificando, podemos citar a duração e o conteúdo do período de desenvolvimento que constituem, por seu envolvimento na vida social e de trabalho, a preparação de uma pessoa; isto é, o período de criação e o treinamento estão historicamente longe de ser sempre os mesmos. Sua duração varia de época para época, alongando-se à medida que as exigências da sociedade fazem este período crescer (LEONTIEV, 2006, p. 65).

Cada atividade principal do desenvolvimento humano (brincar, estudo ou trabalho), que perpassa o sujeito social, modifica-o, dadas as novas condições objetivas que se impõem a ele. Leontiev (2004) afirma que mesmo com as mudanças das atividades, os conteúdos dos sujeitos são únicos e particulares de cada ser sócio-histórico.

Para que o desenvolvimento humano ocorra, Vigotski (2002) indica que é necessária uma intervenção humana que acione compartilhamentos de conhecimentos entre os sujeitos, desenvolva os diferentes tipos de saberes e de linguagens e possibilite as apropriações dos significados sociais. As ações sociais dos sujeitos sobre o mundo pressupõem mediações, seja do homem com os objetos, seja do homem com outros homens.

As relações com o mundo são constantemente mediadas por outras pessoas ou por objetos que também são resultados de relações humanas. O desenvolvimento mental dá-se por meio do desenvolvimento das funções psíquicas novas, a partir desses campos relacionais, sendo a comunicação uma condição imprescindível para que aconteça a mediação entre os sujeitos envolvidos. Tal ato é conceituado por Vigotski (2003) como mediação. É por ele que ocorre o desenvolvimento das funções psicológicas superiores para a formação do homem social.

O conceito de mediação na teoria histórico-cultural possui um lugar central, devido às funções psicológicas superiores serem processos organizados e desenvolvidos, primeiro, no plano do contexto social para, em seguida, construírem significações pessoais no sujeito.

A criança não está de modo algum sozinha em face do mundo que a rodeia. As suas relações com o mundo têm sempre por intermédio a relação do homem aos outros seres humanos; a sua atividade está sempre inserida na comunicação. A comunicação, quer esta se efetue sob a sua forma exterior, inicial, de atividade em comum, quer sob a forma 
de comunicação verbal, ou mesmo apenas mental é a condição necessária e específica do desenvolvimento do homem na sociedade (LEONTIEV, 2006, p. 7).

A formação das funções psicológicas superiores dá-se por meio de atividades culturalmente mediadas. A mediação é um processo de intervenção que auxilia o sujeito na constituição do pensamento, que não se organiza de maneira direta, apenas pela palavra, seu aspecto sonoro. Por ser complexo, o pensamento desenvolve-se a partir dos significados das palavras. Pela mediação, os sujeitos conseguem romper com a ordem direta (pensamento-palavra) e constroem mediações que estabelecem uma via indireta para alcançar o desenvolvimento do pensamento.

O pensamento não está somente externamente mediado por signos, e sim também internamente por significados. A comunicação imediata entre consciências é impossível física e psicologicamente. Isto só pode ser conseguido por uma via indireta e mediada. Este caminho consiste na mediação interna do pensamento, primeiro através dos significados e logo depois através das palavras. Por isso, o pensamento nunca é equivalente ao significado direto das palavras. $\mathrm{O}$ significado medeia o pensamento em seu caminho para a expressão verbal, ou seja, o caminho do pensamento à palavra é um caminho indireto e internamente mediado (VIGOTSKI, 2002, p. 508).

A nossa mente elabora os conceitos por intermédio dos signos mediados culturalmente. Vigotski (2003) defende que a linguagem é o principal recurso do homem para a organização e elaboração de conceitos. A atividade humana diferencia-se da dos animais por ser intencional e consciente; tais características são impulsionadas pela linguagem.

Não nos tornamos humanos por meio deheranças genéticas. Temos que aprender a ser humanos, o que ocorre à medida que incorporamos as instâncias sociais e históricas da cultura da humanidade. Diante disso, compreender como ocorre o processo de humanização auxilia no nosso desenvolvimento e, como consequência, no desenvolvimento da nossa consciência (ARAUJO, 2003).

O conceito de infância presente no projeto da União das Repúblicas Socialistas Soviéticas (URSS), que está em consonância com a teoria histórico-cultural, parte da valorização do processo de aprendizagem, sendo por meio dele que ocorre a apropriação dos instrumentos culturais e das relações criadas por estes. O processo de humanização está interligado ao processo de educação, discussão que será aprofundada no próximo item.

Os baixos investimentos em políticas para a infância no Brasil nas últimas décadas (SAVIANI, 2008) retratam uma sociedade que define a infância de maneira homogênea, padronizando as crianças, desconsiderando os fatores sociais e evidenciando apenas suas características biológicas. É possível, em muitas situações atuais, visualizar em líderes políticos concepções sobre a infância análogas às presentes na Idade Média, retratadas por Ariès (1978).

Desde a administração federal do período de Fernando Henrique Cardoso (1995-2001), a influência que o Banco Mundial ${ }^{1}$, a partir da sua capacidade financiadora, exerce sobre as políticas infantis

\footnotetext{
${ }^{1} \mathrm{O}$ banco é propriedade de 181 países-membros cujas perspectivas e interesses são representados por um conselho diretor sediado em Washington. Banco Mundial é uma denominação genérica para numerosas instituições financeiras internacionais,
} 
é desastrosa, ocasionando programas de baixo custo na educação básica, com intuito de preservar seus interesses políticos e ideológicos.

O Banco Mundial e outras agências doadoras, supõem que as crianças pequenas passam pelos mesmos estágios de desenvolvimento nas mesmas idades, tanto em regiões remotas do Nepal como em Chicago. Para essa concepção, o que define a primeira infância é a capacidade cerebral. "Se o cérebro se desenvolve bem, o potencial de aprendizagem aumenta e as possibilidades de fracasso na escola ou em período posterior da vida diminuem.” (PENN, 2002, p. 15).

Os maiores acionistas do Banco Mundial são os Estados Unidos, seguidos do Japão e Reino Unido. É importante retratar que as principais intenções do banco são direcionadas aos países em desenvolvimento ou em transição, apresentando-se como uma conexão entre as nações pobres e as nações ricas.

As ações direcionadas para a infância tangem ao objetivo de organizar um adulto plenamente produtivo, "capital humano do futuro". A partir dessa concepção, foi realizado pelo World Bank Institute um manual contendo orientações para a infância (PENN, 2002).

O manual e as demais ações do banco e de seus parceiros são justificados pelos mesmos discursos de preocupação com os demais países denominados em desenvolvimento ou em transição, buscando ser um suporte para a reconstrução de economias debilitadas, promovendo um salto desenvolvimentista em tais países.

O neoliberalismo, ideologia que organiza o sistema capitalista e é seguida pelo Banco Mundial e seus parceiros, defende que o homem é livre em suas relações de trabalho. Por meio da meritocracia, ele pode alcançar seus sucessos particulares em detrimento dos demais sujeitos sociais.

Charlot (1983) indica que a liberdade proposta pelo liberalismo é relativa, porque o homem, sendo um ser social, possui condições sociais diferenciadas. Por exemplo: uma criança que é filha de um sapateiro decide tornar-se médica. Ela encontrará em seu percurso escolar diversas dificuldades para realizar a graduação e tornar-se médica. Ao passo que uma criança filha de um médico terá suportes sociais e econômicos para a efetivação de seu desejo escolar.

[...] essa liberdade apresenta sempre uma forma determinada, em condições sociais determinadas. Por exemplo, o indivíduo é teoricamente livre para escolher a profissão que deseja exercer. Mas é, na realidade, submetido ao mercado de trabalho regido pelas leis do sistema capitalista, leis que exprimem a opressão de uma classe social por outra e que contradizem, assim, o conteúdo teórico da idéia de liberdade. O uso ideológico da idéia de liberdade consiste em tratar a Liberdade como uma idéia autônoma e justificar, pela idéia de Liberdade, a ausência de liberdade efetiva nas condições concretas de existência (CHARLOT, 1983, p. 18-19).

A discussão sobre classes sociais é de relevância para o estudo da infância para compreendermos

como o Banco de Pesquisa e Desenvolvimento (Bird) e a Associação Internacional de Corporação Financeira e Desenvolvimento Internacional (PENN, 2002, p. 9). 
que as concepções do ser criança são diferenciadas, devido aos interesses de classe. Também é importante pensar a infância como uma construção histórica e social (CHARLOT, 1983), em que a criança é constituída por meio de suas condições materiais objetivas, negando um desenvolvimento humano baseado em uma essência abstrata e natural.

Mesmo com a influência econômica do Banco Mundial no cenário educacional infantil, alguns avanços legais no Brasil foram alcançados a favor dos direitos dos pequenos. Tais avanços obtidos nas últimas décadas na legislação referente aos direitos e deveres da criança brasileira têm sido significativos.

O Estatuto da Criança e do Adolescente (ECA) (BRASIL, 1990) representa um avanço legal e conceitual quanto à infância, pois considera a criança como um sujeito de direitos, cuja responsabilidade pelo seu bem-estar é não só da família, mas também do poder público. A legislação brasileira, de acordo com o artigo 29 da Lei no 9.394/96, Lei de Diretrizes e Bases da Educação Nacional (LDB), tem assegurado o atendimento à criança em benefício de seu desenvolvimento, reconhecendo a importância do "[...] desenvolvimento integral da criança até os seis anos de idade, em seus aspectos físico, psicológico, intelectual e social, complementando a ação da família e da comunidade” (BRASIL, 1996).

O avanço legislativo de reconhecer a criança como um ser social nem sempre se faz presente na prática, no contexto social real, devido a predominância nas gestões públicas em conceber a criança de acordo com os interesses políticos e ideológicos de cada governo, como também pela influência do Banco Mundial e de outros organismos internacionais.

Conforme já afirmado, há contextos sociais, na contemporaneidade, nos quais as crianças não são reconhecidas como sujeitos reais, atuantes em um coletivo social, mas vistas como seres frágeis, cujas habilidades e capacidades só serão desenvolvidas em um determinado estágio da infância. Do ponto de vista teórico, tal concepção de infância, além de contraditória com a legislação atual, idealiza a criança e a infância com determinados períodos de desenvolvimento, regidos por leis biológicas, o que não contribui com práticas que auxiliam no desenvolvimento pleno da criança.

Saberes escolares para que e para quem? Ponderações sobre o processo de constituição do conhecimento

O homem não nasce humano. A partir de suas apropriações da cultura da sociedade, ele se torna humano, ou seja, ser humano não é inato do sujeito e não se restringe apenas a aspectos biológicos do desenvolvimento. Humanizar-se é uma ação socialmente construída por meio das apropriações sociais de cada indivíduo (LEONTIEV, 2004).

As experiências construídas e organizadas pela humanidade não são inatas aos indivíduos, as apropriações de saberes não são automáticas. Para que ocorram, é necessária uma mediação entre o indivíduo e o conhecimento. O encontro deles é mediatizado por outros homens, por meio da prática social. Leontiev (2004) afirma que o homem que vive isolado da sociedade não poderá se apropriar do que é humano, desde valores e sentimentos (amizade, amor, coragem etc.) até as situações práticas, como 
utilizar talheres, uma vez que a ausência das relações sociais impede o desenvolvimento humano e a apropriação social.

Considerando a tese da teoria da atividade (LEONTIEV, 2004), a principal atividade pela qual o homem se humaniza e desenvolve sua cultura é o trabalho. Somam-se a essa atividade o estudo e o brincar, já que, tal como o trabalho, elas produzem o humano no homem. O trabalho possui um papel central na história da humanidade, configurando a ruptura entre os homens e os animais.

Leontiev (2004) marca que a diferença essencial entre os processos de adaptação, realizada pelos animais, e os de apropriação, pelo homem, ocorre na medida em que a apropriação dialoga com o desenvolvimento humano historicamente formado, diferenciando-se da organização adaptativa, a qual se fundamenta a partir da hereditariedade, ou seja, “[...] a encarnação nas propriedades do indivíduo das aquisições do desenvolvimento da espécie" (LEONTIEV, 2004, p. 181).

O homem, para constituir um ser humano, organiza suas atividades e, por meio delas, transformase em um sujeito ativo e consciente de suas ações e necessidades. Tais conhecimentos desenvolvidos nas atividades de trabalho foram acumulados e transferidos de geração a geração. Esse movimento não se organiza por meio de uma transmissão hereditária do conhecimento, mas por intermédio de uma relação social e histórica com o conhecimento baseada na materialidade (LEONTIEV, 2004).

O homem não nasce dotado das aquisições históricas da humanidade. Resultando estas do desenvolvimento das gerações humanas, não são incorporadas nem nele, nem nas suas disposições naturais, mas no mundo que o rodeia, nas grandes obras da cultura humana. Só apropriando-se delas no decurso da sua vida ele adquire propriedades e faculdades verdadeiramente humanas. Este processo coloca-o, por assim dizer, aos ombros das gerações anteriores e eleva-o muito acima do mundo animal (LEONTIEV, 2004, p. 282-283).

Ao trabalhar com o conceito de conhecimento, é importante levar em consideração o princípio de que a organização da atividade humana, seja ela o trabalho, o estudo ou o brincar, é fundada na historicidade e na materialidade. Por meio da atividade principal, é possível compreender o conhecimento em uma perspectiva não descritiva e restrita, a partir da compreensão e ação da realidade objetiva dos sujeitos educandos.

A educação constitui-se pelas relações sociais. Marx (1989), ao dimensionar a consciência como uma característica humana social, valoriza as relações humanas e as transformações organizadas por ela, valendo-se das atividades realizadas em tais relações, negando, por sua vez, uma consciência inata, colocando-a como um produto cultural, histórico, material e social. Como reitera o teórico revolucionário, "Não é a consciência dos homens que determina o seu ser; ao contrário, é o seu ser social que determina a sua consciência” (MARX, 1989, p. 233).

A apropriação de novos conhecimentos ocorre nas relações sociais. Sendo o espaço escolar o contexto em que é regulamentado o exercício do educar, ele acaba por reproduzir valores de determinados grupos sociais. A escola, como a sociedade, também se organiza em um sistema de classes 
sociais. Ela reproduz valores, crenças e opiniões de um complexo cultural classista. Com isso, tais valores penetram e se legitimam no social.

O movimento histórico e os conhecimentos acumulados pela humanidade só se mantêm vivos pelos ensinamentos, pelos compartilhamentos de saberes que ocorrem de uma geração para outra. Leontiev (2004) nomeia esse movimento histórico de educação. Diante disso, as escolas, em sua maioria, ao se organizar em contexto classista, promovem uma valorização em prol de um determinado grupo social, fazendo com que o movimento histórico organizado pelos ensinamentos e pelas mediações culturais privilegie alguns em detrimento de muitos.

É necessária a defesa de que as condições de apropriação da humanidade são diferenciadas, o que possibilita melhores condições de apropriação do conhecimento a certos sujeitos. A simples culpabilização do aluno por não deter certos conhecimentos, presente em contextos escolares, alerta para a ausência de ações efetivas na organização de uma relação de ensino-aprendizagem que desenvolva apropriações das objetivações humanas, independente do contexto social e das classes sociais de cada criança.

As crianças têm vivências diferenciadas e marcadas por lugares sociais diversos, determinados pelas condições econômicas, sociais e culturais que cada sujeito experimenta e vive. A educação contribui para o processo da humanização, desenvolvendo aptidões humanas nos sujeitos sociais. A escola é o local de acesso à cultura e aos conhecimentos historicamente produzidos pela humanidade, devendo organizarse em um espaço comum e valendo-se de processos mediadores que corroboram o desenvolvimento da coletividade.

As aquisições do desenvolvimento histórico das aptidões humanas não são simplesmente dadas aos homens nos fenômenos objetivos da cultura material e espiritual que os encarnam, mas são aí apenas postas. Para se apropriar destes resultados, para fazer deles as suas aptidões, "os órgãos da sua individualidade", a criança, o ser humano, deve entrar em relação com os fenômenos do mundo circundante através doutros homens, isto é, num processo de comunicação com eles. Assim a criança aprende a atividade adequada. Pela sua função, este processo é, portanto, um processo de educação (LEONTIEV, 2004, p. 272).

Data-se a importância da concepção do desenvolvimento da criança como um processo social composto por meio das experiências e vivências presentes na infância, não se estabelecendo apenas por fatores naturais e biológicos. Para que o desenvolvimento das aptidões humanas aconteça, é necessária a comunicação entre os sujeitos, valendo-se da educação, organizada sobre a concretude da infância.

As riquezas materiais concentradas em apenas uma classe social acabam por legitimar, no contexto social, uma determinada cultura em detrimento de outras. Com isso, crianças trabalhadoras, que em muitas situações não possuem as mesmas oportunidades e experiências de outras crianças, têm maiores dificuldades para se apropriar de alguns conhecimentos historicamente produzidos no contexto escolar, muitas vezes por não terem vivências e mediações com a cultura.

Sendo assim, a atividade de estudo da criança passa a ser prejudicada em muitas situações, pois a 
instituição escolar, ao privilegiar o ensino baseado na cultura de uma determinada classe social em detrimento de outras, escolhe suas práticas pedagógicas pelas apropriações culturais da classe social que concentra as riquezas materiais, negando as diferentes condições de desenvolvimento das crianças.

A concentração de riquezas materiais nas mãos de uma classe dominante é acompanhada de uma concentração da cultura intelectual nas mesmas mãos. Se bem que as suas criações pareçam existir para todos, só uma ínfima minoria, tem o vagar e as possibilidades materiais de receber a formação requerida, de enriquecer sistematicamente os seus conhecimentos e de se entregar à arte; durante esse tempo os homens que constituem a massa da população, em particular da população rural, têm de contentar-se com o mínimo de desenvolvimento cultural necessário à produção de riquezas materiais nos limites das funções que lhes são destinadas (LEONTIEV, 2004, p. 275-276).

Para Vygotsky (1988), o desenvolvimento humano perpassa as experiências humanas, ou seja, o desenvolvimento das funções psicológicas superiores dá-se pela mediação cultural. Tal compreensão rompe com uma visão biologizante bastante difundida acerca do desenvolvimento infantil, razão pela qual a escola, como campo de excelência das mediações culturais, é determinante na formação social da mente.

Cabe à escola organizar o processo de aprendizagem. Para tanto, esse espaço precisa ser marcado por um processo que compreenda o desenvolvimento infantil como um processo dialético, repleto de determinantes sociais. Como reitera Asbahr (2011, p. 42), “[...] não cabe à escola esperar que a criança amadureça. Ao contrário, é seu dever criar condições para que a maturação efetive-se".

A diversidade dos contextos sociais resulta em diferentes concepções educacionais na sociedade, que se modificam de acordo com a ideologia, vivências e interesses de cada grupo social. Tais concepções interferem significativamente nas ações políticas de cada instância governamental, seja ela de ordem pedagógica, dentro de uma sala de aula, de ordem institucional, como prefeituras e agências reguladoras, ou mesmo de uma ordem social mais ampla, representada por órgãos multilaterais como a Unesco, o Banco Mundial e o Fundo Monetário Internacional.

$\mathrm{Na}$ contemporaneidade ocorre uma desvalorização dos princípios humanistas. As principais áreas do conhecimento estão distanciadas dos valores humanos devido à ordem mercadológica que impõe uma cisão entre os valores humanos e os dos conhecimentos. O mercado promove e financia um conhecimento que legitima a desigualdade, beneficiando apenas alguns indivíduos, em benefício da produtividade, do lucro e da vantagem. Trata-se hoje da hegemonia da ideologia neoliberal (CARVALHO, 1998), que vivifica o princípio da meritocracia, marcado pela lógica de que cada um recebe aquilo de que é merecedor.

A escola, ao assumir tais princípios, assume igualmente que a apropriação dos conhecimentos pelos sujeitos dá-se de acordo com seus méritos individuais. Com isso, desobriga-se de configurar-se como um espaço no qual seja possível criar, vivenciar novos sentidos e significados do conhecimento para si e com o mundo. Na própria escolha escolar dos conhecimentos científicos, realiza-se uma seleção 
do que é ou não importante e para quem é importante ${ }^{2}$. Nessa seleção ocorre uma privação de determinados saberes e práticas, uma vez que a seleção dos conteúdos é realizada pela classe social dominante, que em muitas situações desconsidera a função social da escola.

Diante disso, a figura do educador assume função vital, o que implica a ciência da importância de sua definição política ante as contradições sociais, já que, compreendendo que vivemos em uma sociedade de classes, “[...] a prática pedagógica é também uma prática política” (MAKARENKO, 1981, p. 10). As concepções pedagógicas serão refletidas na formação de novos adultos. Portanto, faz-se necessário que o educador reconheça e compreenda como se organiza a sociedade de classes e se defina entre a pedagogia dos trabalhadores ou a pedagogia do capital.

Esta concepção dominava e domina a sociedade burguesa, mas a idéia de uma educação apolítica ou neutra não passa de uma hipocrisia da burguesia, um meio de enganar as massas. A burguesia dominante nos países capitalistas entretém cuidadosamente este engodo (LENIN, 25 ago. 1918 apud PISTRAK, 2000, p. 22).

A educação é política. Não existe neutralidade política no movimento de ensino-aprendizagem. Por meio dele, organizam-se modelos sociais, ideias políticas, ou seja, a escola possui paradigmas de comportamentos, das relações de trabalho, dos relacionamentos, dos dogmas. Como diria Vigotski (1995), pela instrução há o desenvolvimento de uma conduta cultural.

A criança, sendo um ser social, localiza-se em alguma dessas classes, reproduzindo os interesses delas por meio de suas experiências de vida. A escola, em muitas situações, busca defender conhecimentos e saberes homogêneos entre os alunos, pela difusão dos modelos sociais das classes dominantes, ignorando os saberes das demais classes.

[...] a sociedade é dividida em classes, não somente diferentes, mas ainda antagônicas. Essas classes sociais têm concepções diferentes da vida, do trabalho, das relações humanas, etc., e traduzem essas concepções em seus ideais. Ora, a criança participa dessa divisão em classes da sociedade, por intermédio da família a que pertence. Tornase assim mais ou menos hábil para exprimir seus estados de espírito, para fazer um trabalho manual, para manter certos tipos de relações com os outros, etc. Ela compreende, segundo o seu meio de vida, o que é a linha de montagem, uma relha de arado, um estetoscópio ou um dicionário. Concebe o trabalho de forma diferente, segundo seja filha de operário, de camponês ou de advogado (CHARLOT, 1983, p. 15).

É fato que a criança nem sempre se reconhece em determinada classe social, sobretudo porque recebe forte influência das classes sociais dominantes, por exemplo, a partir da incorporação de modelos sociais da classe dominante pelas instituições escolares, o que revela a atenção política e ideológica das instâncias educacionais. A maneira pela qual a escola oferece às crianças modelos e concepções das classes dominantes representa um sentido político, na medida em que os interesses de tais grupos são mantidos e garantidos. Ou seja, a educação, em vez de ser libertadora, apresenta-se a serviço da classe social

\footnotetext{
${ }^{2}$ Como exemplo, temos a recente Reforma do Ensino Médio, promulgada como Medida Provisória no 746, de 2016, que alterou a LDB (BRASIL, 1996).
} 
dominante (FREIRE, 1993).

É verdade que, no contexto social capitalista, o conhecimento torna-se cada vez mais distante do trabalhador. Como reitera Freire (1993), o capitalismo não valoriza o conhecimento geral, universal, valendo-se dos saberes específicos, os quais não agregam a criticidade e o desenvolvimento de uma consciência. A era do capital concebe o conhecimento como uma mercadoria, tornando-o uma propriedade privada, a qual poucos sujeitos têm acesso.

Sabemos, no entanto, que na produção material capitalista, o conhecimento, embora seja instrumento para a confecção de um produto, está separado do trabalhador. Planejamento e execução, trabalho intelectual e trabalho manual tornam-se momentos separados. Nesse modo de produção, não é necessário saber para fazer. A divisão pormenorizada do trabalho desqualifica o trabalhador, o destitui do seu saber (RIGON; ASBAHR; MORETTI, 2010, p. 33).

Para Freire (2003, p. 22), “ensinar não é transferir conhecimento, mas criar as possibilidades para a sua produção ou a sua construção". Em consonância com esse pensamento, para a psicologia históricocultural, o desenvolvimento do conhecimento no e para o homem dá-se por meio da atividade prática dominante. A partir dela, configuram-se possibilidades e novas construções cognitivas, sendo ela um movimento individual e coletivo capaz de desenvolver a consciência e as funções psicológicas superiores nos sujeitos.

Diferentemente da relação entre os animais e a natureza, que é, via de regra, uma relação imediata entre estímulos e respostas ou produzida por reações instintivas, a atividade humana supera definitivamente o caráter imediato do psiquismo, pois é mediada por instrumentos psicológicos (ASBAHR, 2011, p. 30).

Reconhecer o estudo como atividade da criança (LEONTIEV, 2004) possibilita assumir um movimento educacional libertador e criativo, considerando o conhecimento como uma produção humana. Tal conceito de atividade retrata que o lugar social ocupado pelo sujeito é fundante para ele constituir suas atividades principais como homem. No caso, a atividade de estudo possibilita que a criança desenvolva o pensamento teórico, caracterizado pela reflexão, análise e ação mental (DAVIDOV, 1988). Isso implica defender uma posição na qual a atividade não é realizada apenas no plano individual, mas também no social, dando importância ao outro, na organização/aplicação/construção da atividade humana, por meio de ações partilhadas com outras pessoas, as quais possuem o domínio das ações e operações do conhecimento acumulado historicamente.

A educação é entendida, na perspectiva teórica que assumimos, como uma via para o desenvolvimento psíquico e principalmente humano, e não como mera aquisição de conteúdos ou habilidades específicas. E é com base nesse posicionamento que afirmamos a necessidade da presença da educação sistematizada em todas as fases de desenvolvimento, dado que ela permite uma organização consciente dos processos de formação dos indivíduos, via organização intencional de um ensino que permita aos sujeitos a apropriação de conhecimentos, de habilidades e de formas de comportamentos produzidos pela humanidade. Nesse sentido, a escola é instituição 
privilegiada no que diz respeito às possibilidades de humanização do homem (RIGON; ASBAHR; MORETTI, 2010, p. 28).

A instituição escolar ao assumir como princípio "ensinar os sujeitos a pensar teoricamente", assume, igualmente, que o conteúdo do pensamento teórico forma-se pelas mediações escolares. A formação do pensamento teórico ocorre por meio da atividade (LEONTIEV, 2004) que se organiza por processos externos (interpessoais) que são internalizados, construindo socialmente a consciência, no processo de análise, reflexão e ação mental. A atividade será internalizada se for organizada a partir das necessidades e motivos do sujeito.

[...] Davydov destaca a peculiaridade da atividade da aprendizagem, entre outros tipos de atividade, cujo objetivo é o domínio do conhecimento teórico, ou seja, o domínio de símbolos e instrumentos culturais disponíveis na sociedade, obtido pela aprendizagem de conhecimentos das diversas áreas do conhecimento. Apropriar-se desses conteúdos - das ciências, das artes, da moral - significa, em última instância, apropriar-se das formas de desenvolvimento do pensamento. Para isso, o caminho é a generalização conceitual, enquanto conteúdo e instrumento do conhecimento (LIBÂNEO, 2004, p. 12).

Diante disso, é primordial na apropriação dos conhecimentos que ocorra uma relação entre a atividade externa apresentada pela criança e suas operações mentais, fato que revela o caráter prospectivo do ensino no desenvolvimento mental dos sujeitos. A criança, ao estabelecer um pensamento teórico sobre o objeto de estudo, cria estruturas cognitivas que lhe possibilitam as transições mentais do conhecimento escolar para as situações práticas e concretas do seu cotidiano, uma vez que, dessa forma, o conceito é internalizado, o que permite a ela se apropriar do objeto de estudo.

O homem cuja vida não se limita ao trabalho intelectual, mas que tem diversos tipos de atividade física entre outras, tem também um pensamento de aspectos diversos. Este pensamento não se fixa, portanto, em pensamento abstrato e a passagem do pensamento à atividade prática efetua-se como um ato absolutamente natural. Este pensamento é sempre um momento da vida total do indivíduo que se desvanece e se reproduz consoante a necessidade se faz sentir (LEONTIEV, 2004, p. 127-128).

A organização das atividades deve impulsionar a criança a pensar, afastando-se de ações descritivas e classificatórias, as quais não são suficientes para se compreender a diversidade de situaçõesproblema vivenciadas pelo homem em sua vida prática e de soluções criadas historicamente. O desenvolvimento do pensamento teórico visa a possibilitar que a criança, pela atividade de estudo, na dimensão de um objeto de estudo (ex. conceito científico), compreenda as múltiplas determinações do objeto de conhecimento humano (NASCIMENTO, 2014).

Para o ensino impulsionar o desenvolvimento do pensamento teórico na criança, as atividades devem estruturar-se por ações de acompanhamento, aprendizagem e avaliação, de modo que o objeto da atividade de estudo reproduza a experiência social do objeto da atividade humana, como defende Nascimento (2014). Na atividade pedagógica isso significa assumir, como indicou Vigotski (1995), que o processo de aprendizagem promove o desenvolvimento, uma vez que as funções psicológicas são antes 
funções sociais.

O homem, em sua constituição como ser humano, organiza suas atividades e, por meio delas, transforma-se em um sujeito ativo e consciente de suas ações e necessidades. Tais conhecimentos desenvolvidos nas atividades de trabalho foram acumulados e transferidos de geração a geração por intermédio de uma relação social e histórica com o conhecimento (LEONTIEV, 2004).

A escola, quando realiza atividades que dificultam a conexão entre o significado social e o sentido pessoal dos alunos, impossibilita que a criança compreenda o motivo social e o objeto da atividade. Tal cisão entre o significado social e o sentido pessoal da atividade constitui um processo de alienação. Para Leontiev (2004), a atividade humana está em constante relação com o seu desenvolvimento, que só ocorre mediante a compreensão da atividade realizada pelo sujeito.

Os motivos presentes no contexto escolar são forças internas das crianças que atuam de forma significativa no processo de aprendizagem, mas que dependem das ações externas - atividade de ensino adequada. A atividade de estudo antecede, mas não antecipa, a atividade de trabalho. $\mathrm{O}$ estudo deve desenvolver na criança as ferramentas psicológicas necessárias para que ela consiga elaborar sua próxima atividade, que é a do trabalho.

Assim, a atividade de estudo desenvolvida pela criança na instituição escolar deveria ser a atividade que a formaria como sujeito social, sendo, portanto, a sua principal atividade. Esta atividade, sendo sua principal, proporcionaria a formação de sua consciência pessoal e social, pelo processo de apropriação das objetivações humanas. Com isto, defende-se que, mesmo com a ideologia liberal, é possível, ainda que circunstancialmente, fazer da escola um ambiente em que os conhecimentos da humanidade sejam apropriados de modo que os estudantes desenvolvam uma consciência social capaz de compreender a realidade de forma crítica e, sobretudo, humana.

\section{REFERÊNCIAS}

ARAUJO, E. S. Da formação e do formar-se: a atividade de aprendizagem docente em uma escola pública. 2003. Tese (Doutorado em Educação) - Faculdade de Educação, Universidade de São Paulo, São Paulo, 2003.

ARIÈS, P. História social da infância e da família. Tradução: D. Flaksman. Rio de Janeiro: LCT, 1978.

ASBAHR, F. da S. F. "Por que aprender isso, professora?” Sentido pessoal e atividade de estudo na psicologia histórico-cultural. 2011. Tese (Doutorado em Psicologia) - Instituto de Psicologia, Universidade de São Paulo, São Paulo, 2011.

BRASIL. Estatuto da Criança e do Adolescente. Brasil: República Federativa do Brasil, 1990. 
BRASIL. Lei ño 9.394, de 20 de dezembro de 1996. Lei de Diretrizes e Bases da Educação Nacional. Brasília, DF: Ministério da Educação, [1996]. Disponível em: http://portal.mec.gov.br/seesp/arquivos/pdf/lei9394_ldbn1.pdf. Acesso em: 15 ago. 2015.

CARVALHO, D. P. de. A nova lei de diretrizes e bases e a formação de professores para a educação básica. Revista Ciência e educação, Bauru, v. 5, n. 2, p. 81-90, 1998. Disponível em: http://www.scielo.br/scielo.php?script=sci_arttext\&pid=S1516-73131998000200008. Acesso em: 17 ago. 2015.

CHARLOT, B. A mistificação pedagógica. Realidades sociais e processos ideológicos na teoria da educação. Rio de Janeiro: Zahar editores, 1983.

DAVIDOV, V. La enseñanz̧a escolar y el desarrollo psíquico. Moscou: Progresso, 1988.

DRUMMOND, C. Reunião Drummond - 10 livros de poesias. 5. ed. Rio de Janeiro: Editora José Olympio, 1973.

FREIRE, P. Pedagogia do oprimido. 21. ed. Rio de Janeiro: Paz e terra, 1993.

FREIRE, P. Pedagogia da autonomia. 30. ed. Rio de Janeiro: Paz e Terra, 2003.

LEONTIEV, A. O desenvolvimento do psiquismo. Tradução Rubens Eduardo Frias. São Paulo: Centauro, 2004.

LEONTIEV, A. Os princípios psicológicos da brincadeira pré-escolar. In: VIGOTSKI, L. S.; LURIA, A. R.; LEONTIEV, A. N. Linguagem, desenvolvimento e aprendizagem. 10. ed. São Paulo: Ícone Editora, 2006. p. 119-142.

LIBÂNEO, J. C. A didática e a aprendizagem do pensar e do apreender: a Teoria Histórico-cultural da atividade e a contribuição de Vasili Davydov. Revista Brasileira da Educação, Rio de Janeiro, n. 27, p. 5-27, set./dez. 2004. Disponível em: http://www.scielo.br/pdf/rbedu/n27/n27a01. Acesso em: 10 nov. 2015.

MAKARENKO, A. S. Conferências sobre a educação infantil. Tradução de Maria Aparecida Abelaira Vizotto. São Paulo: Editora Moraes, 1981.

MARX, K. Manuscritos econômico-filosóficos. Lisboa: Edições 70, 1989.

MELLO, A. S. Contribuições da teoria histórico-cultural para a educação da pequena infância. Cadernos de Educação, n. 50, p. 1-12, 2015. Disponível em: https://periodicos.ufpel.edu.br/ojs2/index.php/caduc/article/view/5825/4249. Acesso em: 1 dez. 2015.

NASCIMENTO, C. P. A atividade pedagógica da Educação física a proposição dos objetos de ensino e o desenvolvimento das atividades da cultura corporal. 2014. Tese (Doutorado em Educação) - Faculdade de Educação, Universidade de São Paulo, São Paulo, 2014.

PENN, H. Primeira Infância: a visão do Banco Mundial. Cadernos de Pesquisa, São Paulo, n. 115, p. 7-24, mar. 2002.

PISTRAK, M. M. Fundamentos da escola do trabalbo. Tradução Daniel Aarão Reis Filho. São Paulo: Expressão Popular, 2000.

RIGON, A. J.; ASBAHR, F. S. F.; MORETTI, V. D. Sobre o processo de humanização. In: MOURA, M. 
O. (coord.). A atividade pedagógica na teoria histórico-cultural. Brasília: Líber, 2010. p. 13-44.

ROUSSEAU, J.-J. Emílio ou da Educação. Trad. Sérgio Milliet. 3. ed. Rio de Janeiro: Bertrand Brasil, 1995.

SAVIANI, D. Escola e democracia. Campinas: Autores Associados, 2008. (Coleção educação contemporânea).

VIGOTSKI, L. S. Método de investigación. In: VIGOTSKI, L. S. Historia del Desarrollo de las Funciones Psiquicas Superiores. Obras Escogidas. Tradução de Lydia Kuper. Madrid: Visor, 1995. T. III, cap. 2.

VIGOTSKI, L. S. A Formação social da mente. 6. ed. São Paulo: Martins Fontes, 2002.

VIGOTSKI, L. S. Psicologia Pedagógica. Edição Comentada por Guilhermo Blanck. Tradução de Claudia Schilling. Porto Alegre: Artes Médicas, 2003.

VYGOTSKY, L. S. Aprendizagem e desenvolvimento intelectual na idade escolar. In: VYGOTSKY, L. S.; LURIA, A, R.; LEONTIEV, A. N. Linguagem e desenvolvimento e aprendizagem. 5. ed. São Paulo: Ed. Ícone, 1988. p. 103-117. 